\title{
Çok Kriterli Karar Verme Yöntemleriyle Metro Sürücüsü Seçimi
}

\author{
İmran Özcan ${ }^{1}$ \\ Umut Hulusi İnan ${ }^{2}$ \\ Ammar Yasir Korkusuz ${ }^{3}$
}

\begin{abstract}
Çok Kriterli Karar Verme Yöntemleriyle Metro Sürücüsü Seçimi

Öz

Ulaşım sektöründe uygun olmayan personelin seçimi para ve zaman kaybının yanı sıra, kullanıcıların güvenliğini de etkilemektedir. Uygun personel seçimi problemi aslında çok kriterli bir karar verme problemidir. Bu çalışmada bir büyükşehir belediyesi metrosunda vatman olarak çalışacak personelin seçilmesi için çok kriterli karar verme yöntemleri kullanılmıştır. İlk olarak literatür araştırması ve uzman görüşmeleri sonucu kriterler belirlenerek, bu kriterler AHP (Analytic Hierarchy Process) yöntemi ile ağırlıklandırılmıştır. Daha sonra GRA (Grey Relational Analysis) ve TOPSIS yöntemleri ile adaylar sıralanmıştır. İki farklı yöntemin sonuçları kıyaslanarak çalışmanın tutarlılığı incelenmiştir. Personel seçiminde sayısal olmayan kriterlerin sayısallaştırılarak daha objektif seçimler yapılabileceği gösterilmiştir. Yazarların bilgisine göre bu çalışma, literatürde metro sürücüsü seçimi için yapılan ilk çalışmadır. Ayrıca personelin sıralanması aşamasında iki farklı yöntem kullanarak sonuçların tutarlılığını inceleyen nadir çaIışmalardan biridir.
\end{abstract}

Anahtar Kelimeler: İnsan Kaynakları, Personel Seçimi, Çok Kriterli Karar Verme

\section{Metro Driver Selection by Using Multi Criteria Decision} Making Methods

Abstract

Hiring unqualified personnel in transport industry does not only cause money and time waste, but also it affects the safety of users. The selection of the appropriate staff problem is a multi-criteria decision-making problem. In this study, multi criteria decision-making methods are used to select metro driver for a metropolitan municipality. Firstly, criteria were determined by literature research and expert interviews and these criteria were weighted with AHP (Analytic Hierarchy Process) method. After that, candidates are ranked by using GRA (Grey Relational Analysis) and TOPSIS methods. The results of both methods are compared to analyze the consistency of the study. It is shown that non-numeric criteria can be digitized, and this leads to make more objective personnel selection. According to the authors' knowledge, this study is the first in the literature for the selection of subway drivers. Moreover, it is a rare study which uses two different methods to analyze the consistency of results in alternatives' ranking process.

Keywords: Human Resources, Personnel Selection, MultiCriteria Decision Making

\section{Giriş}

Personel seçimi, işe alınacak kişinin özellikleri ile pozisyonun gerektirdiği özelliklerin kıyaslanarak bu pozisyona en uygun adayın belirlenmesidir. Adayın özelliklerini bilmek ve pozisyonun gerekliliklerini tanımlamak, personel seçiminin vazgeçilmez iki unsurudur. Personel seçimi, emek yoğun sistemlerde verimliliği, dolayısıyla kârlılı̆ı etkileyen önemli kararlardan birisidir. Personel seçim kararlarının niteliği ve doğruluğu büyük ölçüde seçilen personelin tecrübesine, yetkinliğine, işe uyumuna, performansına ve kişisel özelliklerine bağlıdır. Bu özelliklerin değerlendirilerek en iyi personelin seçilmesi için yaygın olarak çok kriterli karar verme (ÇKKV) yöntemleri kullanılmaktadır (Adıgüzel, 2009: 243).

Hizmet sektöründe, firmanın insan kaynağı başarıya doğrudan etki etmektedir. Bu nedenle hizmet sektöründeki firmalar için önemli olan, kalifiye ve verimli insan kaynağını seçebilmektir.

\footnotetext{
1 Endüstri Mühendisi, Haliç Üniversitesi, Mühendislik Fakültesi. imranozcan95@gmail.com, Yazar ORCID bilgisi: https://orcid.org/0000-0003-4226-1922

2 Dr. Öğr. Üyesi, Esenyurt Üniversitesi, Mühendislik ve Mimarlık Fakültesi. umutinan@esenyurt.edu.tr, Yazar ORCID bilgisi: https://orcid.org/0000-0001-7316-1700

${ }^{3}$ Dr. Öğr. Üyesi, Esenyurt Üniversitesi, Mühendislik ve Mimarlık Fakültesi. ammarkorkusuz@esenyurt.edu.tr, Yazar ORCID bilgisi: https://orcid.org/0000-0002-3014-3454
} 
Mülakata çağırma ile başlayan işe alım süreci, hem sübjektif (sezgisel) kriterlere hem de objektif (nesnel) kriterlere bağlı olmalıdır. İşletmeye uygun olan ve istenen kriterleri sağlayan kişilerin işletmeye kazandırıması, eğitim ve gelişim sürecini kısaltmaktadır. Bu nedenle önceden belirlenen kriterlere ve iş tanımlarına uyan adayların istihdam edilmesi önemli bir kazançtır (Tureli ve Davraz, 2016: 249).

Personel alımlarında kullanılan rasyonel kriterlerin yanında, irrasyonel kriterlerin de değerlendirilmesi gerekmektedir. Bazen rasyonel kriterlerin birbirine yakın olması veya kriterlerin önem düzeylerindeki farklılıklar, karar verirken matematiksel bir yöntem ihtiyacı oluşturmaktadır. ÇKKV yöntemleri, karar vericilerin kararlarında etkinliğini ve başarısını arttıran, nitel ve nicel değişkenleri aynı anda değerlendiren yöntemlerdir. ÇKKV yöntemleri, personelin istihdam alanının gerektirdiği niteliklerin ve önceliklerin sözel ifadelerinin sayısal verilere dönüşmesini sağlarlar. Bu sayede personel seçiminde tüm kriterler sayısallaştırılarak daha objektif seçimler yapılabilir (Özbek, 2014: 209).

Bu çalışmada, firmalar için önem derecesi en yüksek konulardan biri olan personel seçimi probleminin çözümü için ÇKKV yöntemlerinden faydalanılmıştır. İlk olarak metro sürücüsü seçimi için kriterler belirlenmiş ve AHP yöntemi ile bu kriterler ağırlıklandırılmıştır. Daha sonra, kriter verileri kullanılarak TOPSIS ve GRA yöntemleri ile adaylar sıralanmıştır. İki farklı yöntemin sonuçları benzer çıkmıştır. Adayların iki farklı yöntem ile sıralanarak benzer sonuçların elde edilmesi, sonuçların tutarlılığını göstermektedir. Yazarların bilgisine göre bu çalışma, literatürde metro sürücüsü seçiminde ÇKKV yöntemlerini kullanan ilk çalışma, alternatiflerin sıralanması aşamasında iki farklı yöntem kullanarak sonuçların tutarlılığını analiz eden nadir çalışmalardan biridir.

\section{Literatür}

Literatürde ÇKKV yöntemlerinin personel seçimi alanında kullanılmasına yönelik birçok çaıışma bulunmaktadır. ÇKKV yöntemleri, birden fazla kritere bağlı olarak en iyi alternatifin seçilmesi problemlerinin çözümünde oldukça güçlü yöntemlerdir. Bu nedenle belli bir pozisyona, o pozisyonun ihtiyaçlarını en iyi karşılayan adayın seçilmesi problemi, ÇKKV yöntemleri ile çözülebilir.

Dağdeviren, çalışmasında bulanık AHP kullanarak üst düzey bir yönetici pozisyonuna terfi için başvuran adayları değerlendirmiş ve her bir aday için öncelik değerleri belirlemiştir (Dağdeviren, 2007: 791). Aksakal'ın çalışmasında bir fabrika için endüstri mühendisi pozisyonunda çalışacak personel seçimi için DEMATEL ve ANP (Analytic Network Process) yöntemleri bütünleşik olarak kullanılmıştır (Aksakal ve Dağdeviren, 2010: 905). Afshari ve diğerleri tarafından yapılan çalışmada, telekomünikasyon şirketindeki bir pozisyon için 7 kriter belirlenmiş ve ÇKKV yöntemlerinden SAW (Simple Additive Weighting) yöntemi kullanılarak 5 aday değerlendirilmiştir (Afshari vd., 2010: 511). Afshari ve diğerleri tarafından yapılan başka bir çalışmada ise aynı problem ELECTRE yöntemi ile çözülmüştür (Afshari vd., 2010: 3068). Ablhamid ve diğerleri telekom sektöründeki bir firma için işe alınacak adayın seçiminde bulanık AHP yöntemini uygulamıştır (Ablhamid vd., 2013: 24). Yıldız ve Deveci ise, teknoloji alanındaki bir işletme için bulanık VIKOR kullanarak personel seçimi yapmışlardır (Yıldız ve Deveci, 2013: 427). Eroğlu ve diğerlerinin çalışmasında muhasebe departmanına alınacak personelin seçimi için ÇKKV yöntemlerinden ORESTE kullanılmıştır (Eroğlu vd., 2014: 7). Doğan ve Önder tarafından yapılan çaIışmada satış temsilcisi pozisyonuna aday seçimi için AHP ve TOPSIS yöntemleri entegre olarak kullanılmıştır. Kriter ağırlıklandırması için AHP kullanılmış, aday sıralaması için ise TOPSIS kulla- 
nılmıştır. (Doğan ve Önder, 2014: 5796). Tepe ve Görener'in çalışmasında ise ara kademe yönetici pozisyonuna seçilecek personel için kullanılacak kriterlerin ağırlıkları AHP ile hesaplanmış, ardından MOORA yöntemi kullanılarak personel seçimi gerçekleştirilmiştir (Tepe ve Görener, 2014: 1). Bedir ve Eren'in çalışmasında ise benzer şekilde satış danışmanı pozisyonu için AHP ve PROMETHEE entegre olarak kullanılmıştır (Bedir ve Eren, 2015: 46). Yıldız ve Aksoy'un beraber yaptıkları çalışmada otomotiv yan sanayii alanında çalışan bir firmanın personel seçimi probleminin çözülmesi için AHP yöntemi kullanılmıştır (Yıldız ve Aksoy, 2015: 59). Akın’ın yaptığı çalışmada, bir kamu üniversitesine alınacak araştırma görevlisinin seçilmesi için bulanık TOPSIS yöntemi kullanılmıştır (Akın, 2016: 224). Yine benzer şekilde, Değermenci ve Ayvaz'ın çalışmasında, bulanık TOPSIS kullanılarak katıım bankasında uzman yardımcısı pozisyonu için seçilecek aday belirlenmiştir (Değermenci ve Ayvaz, 2016: 77). Özdemir ve diğerlerinin çalışmasında, personel değerlendirmesi için kullanılabilecek kriterler belirlenmiş ve bu kriterler bulanık ÇKKV yöntemlerinden biri olan CFPR (Consistent Fuzzy Preference Relations) yöntemi ile ağırlıklandırılmıştır (Özdemir vd., 2017: 76). Özdemir ve Nalbant'ın çalışmasında ise personel seçimi için choquet integral yöntemi kullanılmıştır (Özdemir ve Nalbant, 2018: 694). Akça ve diğerleri kamu hastanesinde finans yöneticisi seçimi için ANP yöntemi uygulamıştır (Akça vd., 2018: 133). Efe ve Kurt tarafından yapılan çalışmada bir liman işletmesine alınacak personelin seçimi için sekiz kriter belirlenip bu kriterler AHP yöntemi ile ağırlıklandırılmış, daha sonra bu ağırık verileri ile TOPSIS yöntemi uygulanarak adaylar sıralanmıştır (Efe ve Kurt, 2018: 417). Kuşakçı ve diğerleri tarafından yapılan çalışmada, havacılık sektöründe uzman pozisyonunda çalışacak personel seçimi için MULTIMOORA yöntemi ile AHP-TOPSIS entegre yöntemi kullanılmış ve elde edilen sonuçlar kıyaslanarak çalışmanın tutarlılığı incelenmiştir (Kuşakçı vd., 2019: 96). Yıldırım ve diğerleri tarafından yapılan çalışmada, havacılık sektöründe destek personeli seçimi için ÇKKV yöntemlerinden ARAS (Additive Ratio Assessment) kullanılmıştır (Yildirim vd., 2019: 219).

\section{Yöntem}

Personel seçim problemi, personel seçiminde birden çok kritere dayalı olarak karar vermeyi gerektirmektedir. Bu nedenle çok kriterli karar problemi yapısındadır (Karagöz, 2009: 90). Bu çalışmada ÇKKV yöntemlerinden AHP, TOPSIS ve GRA kullanıımıştır. Belirlenen kriterlerin ağırlıklandırılması aşamasında AHP kullanılmış, adayların sıralanması aşamasında ise TOPSIS ve GRA olmak üzere iki farklı yöntem kullanılarak sonuçların tutarlılığı incelenmiştir.

\subsection{Analitik Hiyerarşi Prosesi (AHP) Yöntemi}

Analitik Hiyerarşi Prosesi yöntemini Thomas L. Saaty 1970'lerde geliştirmiştir. AHP, nitel ve nicel ölçütleri sürece dâhil eden çok kriterli karar verme yöntemidir ve literatürde bu problem türlerinde en çok tercih edilen yöntemlerden biridir (Ozdemir vd., 2016: 1057). AHP, yöneticiler tarafından anlaşılması ve uygulanması kolay bir yöntemdir. Aynı zamanda karar verme sürecinin iyileştirilmesine de yardım edebilecek bir yöntemdir. AHP kullanımı, kriter ve alt kriterlerin üstünlüklerinin belirlenmesi ve sistematik olarak karşılaştırılıp değerlendirilmesi ile gerçekleşmektedir (Dağdeviren ve Eren, 2001: 41). En iyi seçeneğin belirlenmesine yönelik AHP yöntemi hem nitel hem de nicel kriterleri dikkate alması, kullanımının basit ve kolay olması nedeniyle karmaşık karar problemlerinin çözümünde yaygın olarak kullanılmaktadır. Son dönemde karar vermedeki belirsizliklerin azaltılması için bulanık kümelerle AHP'nin birlikte kullanımı olan bulanık AHP (Fuzzy AHP) çalışmaları literatürde göze çarpmaktadır (Tepe ve Kaya, 2019: 3). Karar verme problemlerine hiyerarşik bir yapıda bakmakta, en iyi kararın verilmesi için gerekli kriterleri sistematik olarak analiz ederek, bu parametrelerin öncelik sıralamalarını oluşturmaktadır. AHP'nin 
en önemli ön kabullerinden biri hiyerarşide aynı seviyede bulunan kriterlerin birbirini etkilemediği yani kriterlerin birbirinden bağımsız olduğudur (Dağdeviren vd., 2006: 247).

AHP algoritması, belli adımlardan oluşmaktadır. Bu adımların sonunda kriter ağırlıkları ve alternatif indeksleri elde edilir. AHP adımları şu şekildedir (Saaty, 1990: 12; Eren ve Tuzkaya, 2019: 878; Korkusuz vd., 2018: 709);

1. Illk aşamada karar verme problemindeki alternatifler ve kriterler belirlenir.

2. İkinci aşamada kriterlerin ve alt kriterlerin önem derecelerini bulmak için ikili kıyaslama matrisi oluşturulur. Kriter sayısı " $n$ " olarak alınırsa; " $n x n$ " boyutlu, köşegen bileşenleri " 1 " olan, Eş. 1'de görülen A kare matrisi elde edilir

$$
\mathrm{A}=\left[\begin{array}{cccc}
1 & a_{12} & \cdots & a_{1 n} \\
1 / a_{12} & 1 & \cdots & a_{2 n} \\
\cdot & \cdot & \cdots & \cdot \\
\cdot & \cdot & \cdots & \cdot \\
\cdot & \cdot & \cdots & \cdot \\
\cdot & \cdot & \cdots & \cdot \\
1 / a_{1 n} & 1 / a_{2 n} & \cdots & 1
\end{array}\right]
$$

Kriterlerin ikili kıyaslaması, Tablo 1'de görülen AHP ikili karşılaştırma ölçeği ile yapılır.

Tablo 1: AHP ikili Karşılaştırma Ölçeği

\begin{tabular}{|c|c|}
\hline Önem Değerleri & Tanımlar \\
\hline 1; İki faktör eşit önemde & 1; íki faktör eşit önemde \\
\hline 3; Bir faktör diğerinden daha önemli & 1/3; Bir faktör diğerinden daha az önemli \\
\hline 5; Bir faktör diğerinden çok daha önemli & 1/5; Bir faktör diğerinden çok daha az önemli \\
\hline $\begin{array}{l}\text { 7; Bir faktör diğerinden çok güçlü bir şekilde daha } \\
\text { önemli }\end{array}$ & $\begin{array}{l}\text { 1/7; Bir faktör diğerinden çok güçlü bir şekilde daha az } \\
\text { öneme sahip }\end{array}$ \\
\hline $\begin{array}{l}\text { 9; Bir faktör diğerine kıyasla mutlak şekilde güçlü öneme } \\
\text { sahip }\end{array}$ & $\begin{array}{l}\text { 1/9; Bir faktör diğerine kıyasla mutlak şekilde daha az } \\
\text { öneme sahip }\end{array}$ \\
\hline $2,4,6,8$; Ara değerler & $1 / 2,1 / 4,1 / 6,1 / 8 ;$ Ara değerler \\
\hline
\end{tabular}

Kaynak: (Thomas L. Saaty 1990: 15) (AHP Pair-Wise Comparison Scale)

3. Kıyaslama matrisi elde edildikten sonra kriterlerin ağırlıklarının elde edilmesi aşamasına geçilir. Bunun için ilk olarak her bir eleman, bulunduğu sütundaki bütün değerlerin toplamına bölünür ve elde edilen $c_{i j}$ elemanlarının meydana getirdiği matristeki satır elemanlarının aritmetik ortalaması alınarak $W$ kriter ağırlıkları matrisi oluşturulur.

$$
c_{i j}=\frac{a_{i j}}{\sum_{i=1}^{n} a_{i j}} \rightarrow w_{i}=\frac{\sum_{j=1}^{n} c_{i j}}{n} \rightarrow W=\left[\begin{array}{c}
w_{1} \\
w_{2} \\
\cdot \\
\cdot \\
\cdot \\
w_{n}
\end{array}\right]
$$

4. Sonraki aşamada çalışmanın tutarlılığı incelenir. Karar vericilerin kriterleri kıyaslarken tutarlı olması, sonucun doğruluğunu etkileyecektir. Bu nedenle, yapılan kıyaslama sonrası tutarlıık oranı (consistency ratio) hesaplanarak çalışmanın tutarlılığı araştırılır. Tutarlıık 
oranı hesaplanırken, ilk olarak A kıyaslama matrisi ile W öncelik matrisi çarpılarak D sütun vektörü elde edilir. D sütun vektörünün her bir elemanı, w sütun vektöründeki karşılıklı elemanlara bölündüğünde, elde edilen elemanlarının aritmetik ortalaması, Eş. 3'te görüldüğü üzere kıyaslamanın temel değerini verir.

$$
A * W=D=\left[\begin{array}{cccc}
d_{11} & d_{12} & \cdots & d_{1 n} \\
d_{21} & d_{22} & \cdots & d_{2 n} \\
\cdot & \cdot & \cdots & \cdot \\
\cdot & \cdot & \cdots & \cdot \\
\cdot & \cdot & \cdots & \cdot \\
\cdot & \cdot & \cdots & \cdot \\
d_{n 1} & d_{n 2} & \cdots & d_{n n}
\end{array}\right] \rightarrow \lambda=\frac{\sum_{i=1}^{n} \frac{d_{i}}{w_{i}}}{n}(i=1,2, \ldots, n)
$$

5. $\lambda$ değeri bulunduktan sonra, çalışmanın tutarlılığının ölçülmesi için rassallık indeksi incelenir. Kriter sayısı $n$ 'e bağlı bu indeks için Tablo 2'de verilen rastgele gösterge değerleri kullanılır.

Tablo 2: Rastgele Gösterge (RI) Değerleri

\begin{tabular}{lccccccccc}
\hline Kriter Sayısı (n) & 1 & 2 & 3 & 4 & 5 & 6 & 8 & 9 & 10 \\
\hline $\begin{array}{l}\text { Rastgele Gösterge } \\
(\mathrm{RI})\end{array}$ & 0,00 & 0,00 & 0,58 & 0,90 & 1,12 & 1,24 & 1,32 & 1,45 & 1,49 \\
\hline
\end{tabular}

Kaynak: (Saaty 1987: 171) (Random Consistency Index)

6. Bu aşamada $\lambda, n$ ve $R I$ değerleri kullanılarak tutarlılık oranı (CR: Consistency Ratio) hesaplanır. Tutarlılık oranı (CR) için üst limit 0,1 olarak kabul edilir. Değerin daha fazla çıkması durumunda, çalışmada bir hata olduğu veya karar vericinin tutarsız olduğu belirlenir. $\mathrm{Bu}$ durumda, çalışmanın yenilenmesi gerekir. Eş. 4'te tutarlılık oranının (CR) formülü görülmektedir.

$$
C R=\frac{\lambda-n}{(n-1) R I}
$$

7. Son aşamada, yine AHP ölçeği kullanılarak, belirli bir kriterde her bir alternatif ikili olarak kıyaslanır. Her bir kriter için mx1 boyutunda matrisler meydana gelir ve bunların hepsi yan yana yazıldığında mxn boyutunda karar matrisi elde edilir. Elde edilen karar matrisinin kriter ağırlıkları ile çarpımı ile alternatif skorlarının bulunduğu $L$ sonuç vektörü elde edilir.

$$
L=\left[\begin{array}{cccc}
k_{11} & k_{12} & \cdots & k_{1 n} \\
k_{21} & k_{22} & \cdots & k_{2 n} \\
\cdot & \cdot & \cdots & \cdot \\
\cdot & \cdot & \cdots & \cdot \\
\cdot & \cdot & \cdots & \cdot \\
\cdot & \cdot & \cdots & \cdot \\
k_{m 1} & k_{m 2} & \cdots & k_{m n}
\end{array}\right] \times\left[\begin{array}{c}
w_{1} \\
w_{2} \\
\cdot \\
\cdot \\
\cdot \\
\cdot \\
w_{n}
\end{array}\right]=\left[\begin{array}{c}
l_{1} \\
l_{2} \\
\cdot \\
\cdot \\
\cdot \\
\cdot \\
l_{m}
\end{array}\right]
$$

\subsection{Gri İlişkisel Analiz (Grey Relational Analysis - GRA) Yöntemi}

GRA yöntemi, güçlü bir matematiksel temele dayanır. Alternatif ve kriter sayısı olarak herhangi bir sınırı yoktur. Kriter değerleri olarak sayısal verileri alır ancak bu yöntem kriter ağırlıklandırması yapmaz (Özdağoğlu ve Güler, 2016: 589). Nicel değerleri ve gösterge ağırlıklarını girdi 
olarak alan ve alternatiflerin performans skorlarını çıktı olarak veren bir yöntemdir (Tzeng ve Huang, 2011: 103).

GRA yöntemi, ideal çözüme en yakın olan alternatifi en tercih edilebilir olarak belirler. GRA algoritmasının adımları şu şekildedir (Tzeng ve Huang, 2011: 106; Vatansever ve Akgül, 2018: 5; Korkusuz vd., 2020: 86);

1. İlk aşamada alternatif sayısı ve analiz edilecek kriter sayısı belirlenmeli ve karar matrisi oluşturulmalıdır. Alternatif sayısı n, kriter sayısı m olan bir durum için karar matrisi Eş. 6'da görülebilir.

$$
X=\left[\begin{array}{cccc}
x_{1}(1) & x_{1}(2) & \cdots & x_{1}(m) \\
x_{2}(1) & x_{2}(2) & \cdots & x_{2}(m) \\
\cdot & \cdot & \cdots & \cdot \\
\cdot & \cdot & \cdots & \cdot \\
\cdot & \cdot & \cdots & \cdot \\
\cdot & \cdot & \cdots & \cdot \\
x_{n}(1) & x_{n}(2) & \cdots & x_{n}(m)
\end{array}\right]
$$

2. İkinci aşamada, değerler normalize edilir. Kriter değeri yüksek olanın tercih edilmesi durumunda (boy, hız vb.), ve kriter değeri düşük olanın tercih edilmesi durumunda (maliyet, hata sayısı vb.) farklı formüller kullanılır. Yüksek olanın tercih edildiği durumda normalizasyon formülü Eş. 7'de, düşük olanın tercih edildiği durumda normalizasyon formülü Eş. 8 'de görülebilir.

$$
\begin{aligned}
& x_{i}^{*}(j)=\frac{x_{i}(j)-\min x_{i}(j)}{\max x_{i}(j)-\min x_{i}(j)} \\
& x_{i}^{*}(j)=\frac{\max x_{i}(j)-x_{i}(j)}{\max x_{i}(j)-\min x_{i}(j)}
\end{aligned}
$$

3. Üçüncü aşamada, normalizasyon formülleri ile elde edilen değerler kullanılarak Eş. 9'da görülen yeni matris oluşturulur.

$$
X^{*}=\left[\begin{array}{cccc}
x_{1}^{*}(1) & x_{1}^{*}(2) & \cdots & x_{1}^{*}(m) \\
x_{2}^{*}(1) & x_{2}^{*}(2) & \cdots & x_{2}^{*}(m) \\
\cdot & \cdot & \cdots & \cdot \\
\cdot & \cdot & \cdots & \cdot \\
\cdot & \cdot & \cdots & \cdot \\
\cdot & \cdot & \cdots & \cdot \\
x_{n}^{*}(1) & x_{n}^{*}(2) & \cdots & x_{n}^{*}(m)
\end{array}\right]
$$

Her bir sütunda en yüksek değeri alan elemanların bir araya gelmesiyle oluşturulan dizi referans dizisidir. Bu dizi Eş. 10'da görülebilir.

$$
X_{0}^{*}=x_{0}^{*}(1), x_{0}^{*}(2), \quad \ldots \ldots, x_{0}^{*}(m)
$$

4. Dördüncü aşamada, normalize matristeki sütun değerleri ile referans serisindeki değerlerin farklarının mutlak değerleri hesaplanır ve bulunan değerler kullanılarak mutlak değer matrisi oluşturulur. Mutlak değer matrisinin elemanları Eş. 11'deki formül ile hesaplanır.

$$
\Delta_{i}(j)=\left|x_{0}^{*}(j)-x_{i}^{*}(j)\right|
$$

Mutlak değer matrisi Eş. 12'de görülebilir. 


$$
\Delta=\left[\begin{array}{cccc}
\Delta_{o 1}(1) & \Delta_{o 1}(2) & \ldots & \Delta_{o 1}(m) \\
\Delta_{o 2}(1) & \Delta_{o 2}(2) & \ldots & \Delta_{o 2}(m) \\
\vdots & \vdots & \vdots & \vdots \\
\Delta_{o n}(1) & \Delta_{o n}(2) & \ldots & \Delta_{o n}(m)
\end{array}\right]
$$

5. Beşinci aşamada, mutlak değer matrisindeki değerler kullanılarak, gri ilişki katsayısı hesaplanır. $\zeta$ değeri aşırı değerlerin elenmesi için kullanılan sıfır ve bir aralığındaki bir katsayıdır.

$$
\begin{aligned}
& \gamma_{o i}=\frac{\Delta_{\min }+\zeta \Delta_{\max }}{\Delta_{o i}(j)+\zeta \Delta_{\max }}, \\
& \Delta_{\max }=\max _{i} \max _{j} \Delta_{i}(j), \\
& \Delta_{\min }=\min _{i} \min _{j} \Delta_{i}(j), \zeta \in[0,1]
\end{aligned}
$$

6. Son aşamada, kriter katsayıları kullanılarak, alternatiflerin aldığı indeks değeri olan gri ilişki derecesi $\Gamma_{o i}$ bulunur.

$$
\sum_{j=1}^{m} w(f)=1, \Gamma_{o i}=\sum_{j=1}^{m}\left[w_{i}(j) * \gamma_{o i}(j)\right]
$$

\subsection{TOPSIS Yöntemi}

TOPSIS, Technique for Order Preference by Similarity to Ideal Solution kelimelerinin baş harflerinden oluşmaktadır. TOPSIS yöntemi basit, anlaşılır ve hesaplama etkinliği güçlü bir ÇKKV yöntemidir. Farklı alanlarda yaygın olarak kullanılır ve diğer yöntemlerle entegre olarak kullanılabilir (Ak ve Gul, 2019: 114).

Ana amaç, seçilecek olan alternatifin pozitif ideal çözüme en yakın, negatif ideal çözüme ise en uzak olmasıdır. Yani birden çok kriter ve alternatif olduğu durumda, alternatifler arasından en iyi seçime karar verilmesine imkân sağlayan bir tekniktir. TOPSIS yöntemi, sınırlı sayıda öznel girdiye intiyaç duymasından dolayı, karar vericiler tarafından sıkça kullanılmaktadır. Hem kriter değerleri hem de kriter ağılıkları sayısaldır. İdeal çözüm tüm kriterlerin değerlendirilerek, bu kriterleri en ideal seviyede sağlayan alternatifin seçilmesidir. Eğer tüm kriterleri ideal olarak karşılayan bir alternatif yoksa ideal çözüme en yakın olan alternatif seçilir. TOPSIS yöntemi, özellikle rekabetçi ortamlarda iş yapan firmalar için önemli bir performans değerlendirme yöntemidir. Çoklu kriterleri ve oranlarını dikkate alarak çok kriterli karar verme problemlerinin çözümünde kullanılmaktadır. TOPSIS yönteminin uygulama aşamaları şu şekildedir (Uzun ve Kazan, 2016: 101; Doğan ve Önder, 2014: 5804);

1. TOPSIS uygulamasında, ilk olarak karar matrisi oluşturulur. Karar matrisi başlangıç matrisidir. Satırlar kriterlerden, sütunlarda değerlendirme faktörlerinden oluşmaktadır. Aşağıdaki matris $\mathrm{m}$ alternatif ve $\mathrm{n}$ kriterli bir karar matrisidir.

$$
A=\left[\begin{array}{cccc}
x_{11} & x_{12} & \ldots & x_{1 n} \\
x_{21} & x_{22} & \ldots & x_{12} \\
\vdots & \vdots & \vdots & \vdots \\
x_{m 1} & x_{m 2} & \ldots & x_{m n}
\end{array}\right]
$$

2. İkinci aşama, karar matrisinin normalize edilmesidir. Normalizasyon sayesinde farklı ölçeklerdeki değerlendirmeler aynı ölçeğe getirilerek karşılaştırılabilir. Normalleştirme işlemi karar matrisindeki bileşenlerin tüm bileşenlerin kareleri toplamının kareköküne bölünerek hesaplanır. 


$$
r_{i j}=\frac{x_{i j}}{\sqrt{\sum_{i=1}^{m} x_{i j}^{2}}}
$$

3. Üçüncü aşama, ağırlıklı normalize karar matrisinin oluşturulmasıdır. Kriter ağırlıkları (wj) ile normalleştirilmiş karar matrisinin her bir elemanı (rij) çarpılır.

$$
v_{i j}=w_{j} * r_{i j}
$$

4. Dördüncü aşamada, pozitif ve negatif ideal çözümler elde edilir. TOPSIS yöntemi, her kriterin monoton artan veya azalan bir yönelimde olduğunu kabul etmektedir. $A^{*}$ olarak adlandırılan ideal çözüme ulaşmak için, önceki adımda elde edilen ağırlıklandırılmış normalize matrisin her sütunundaki en yüksek ve en düşük değerler seçilir.

$$
\begin{aligned}
& A^{*}=\left\{\left(\max _{i} v_{i j} \mid j \in J\right),\left(\min _{i} v_{i j} \mid j \in J^{\prime}\right)\right\} \\
& A^{-}=\left\{\left(\min _{i} v_{i j} \mid j \in J\right),\left(\max _{i} v_{i j} \mid j \in J^{\prime}\right)\right\}
\end{aligned}
$$

Burada $J$ fayda kriterini, $J$ ' ise maliyet kriterini belirtmektedir. Alternatifler arasından fayda kriteri için maksimum değer, maliyet kriteri için minimum değer gereklidir. $A^{*}$ en çok tercih edilen alternatifi, $A^{-}$ise en az tercih edilen alternatifi göstermektedir.

5. Bu aşamada, ideal çözümden uzaklık değerleri hesaplanır. Her alternatifin pozitif ideal ve negatif ideal noktalardan uzaklığını bulabilmek için Öklid uzaklığı kullanılır. Elde edilen karar noktalarına ilişkin sapma değerlerinde "Pozitif İdeal Ayrım $\left(S i^{*}\right)^{\prime}$ " ve "Negatif Ideal Ayrım $\left(S i^{-}\right)^{\prime \prime}$ denir. Hesaplanan $S i^{*}$ ve $S i^{-}$sayısı, alternatif sayısı kadardır.

$$
\begin{aligned}
& S_{i}^{*}=\sqrt{\sum\left(v_{i j}-v_{v}^{*}\right)^{2}}, \mathrm{i}=1,2,3, \ldots \ldots, \mathrm{m} \\
& S_{i}^{-}=\sqrt{\sum\left(v_{i j}-v_{v}^{-}\right)^{2}}, \mathrm{i}=1,2,3, \ldots \ldots, \mathrm{m}
\end{aligned}
$$

6. Sonraki aşama, ideal çözüme göreceli yakınlık değerinin elde edilmesidir. Her alternatifin ideal çözüme göreceli yakınlık değerinin $\left(C i^{*}\right)$ hesaplanmasında pozitif ideal ve negatif ideal ayrımlardan yararlanılır. Bunu hesaplamak için negatif ideal ayrım ölçüsü, toplam ideal ayrım ölçüsüne bölünür. İdeal çözüme göreceli yakınlık değeri eşitlik 22 yardımı ile hesaplanır.

$$
C_{i}^{*}=\frac{s_{i}^{-}}{s_{i}^{*}+s_{i}^{-}}, 0 \leq C_{i}^{*}<1
$$

7. Formüle göre negatif ideal çözümden uzaklık değeri arttıkça ideal çözüme yakınlık değeri de artmaktadır. Alternatifin pozitif ideal ayrım değerinin yükselmesi, pozitif ideal çözüme yakınlığı azaltmakta iken negatif ayrım değerinin yüksek çıkması, pozitif ideal çözüme yakınlığı artırmaktadır. Son aşamada ise, her alternatif için göreceli yakınlık değerine göre sıralama yapılır. Alternatifler arasında ideal çözüme en kısa uzaklıktaki alternatif, yani en büyük $C i^{*}$ değerine sahip olan alternatifin en iyi olduğu söylenir. $C i^{*}$ değerleri büyükten küçüğe sıralanarak, alternatiflerin öncelik sıralaması yapılır. 


\section{Personel Seçim Süreci İçin Önerilen Yöntem}

Kamu hizmeti olması nedeniyle ulaşım sektöründe çalışan idari ve destek personelin önemi gün geçtikçe artmaktadır. Genel verimliliği ve kârılığı doğrudan etkileyen ulaşım hizmeti, toplumun genel faydası için yapılır. Toplum hızlı, güvenilir ve konforlu hizmet beklemektedir. İşletme yönetimi sistemli, tutarlı ve sağlıklı bir seçim yaparak beklentileri karşılamak istiyorsa, personel seçimi için ÇKKV yöntemlerinden yararlanabilir.

Personel seçme sürecindeki en önemli nokta, işin başarıyla gerçekleştirilmesinde gerekli olan kişisel ve işle ilgili hangi niteliklerin belirleyici olacağının belirlenmesidir. AHP yöntemi literatürde en yaygın kullanılan kriter ağırlıklandırma yöntemlerinden biridir. Personel seçimi probleminin çözümünde kullanılan her kriter, alternatif seçiminde aynı etkiye sahip değildir. Örneğin adayın iş tecrübesi ile adayın iletişim yeteneğinin sonuca etkisi farklı olabilir. Farklı kriterlerin alternatif seçimine etkisinin belirlenmesi için bu çalışmada AHP yöntemi kullanılmıştır.

TOPSIS güçlü matematiksel altyapıya sahip bir yöntemdir ve personel seçimi çalışmalarında yaygın olarak kullanılır. Personel seçimi probleminde kriterler genelde sayısal ve farklı ölçekte olmaktadır (uzmanlar tarafından verilen puan, sınav sonucu vb.). TOPSIS yönteminin en önemli özelliklerinden biri farklı ölçeklerdeki sayısal kriter verilerini girdi olarak alabilmesidir. Benzer şekilde GRA yöntemi de farklı ölçekteki sayısal kriterleri girdi olarak kullanabilen bir yöntemdir. Hem TOPSIS yöntemi hem de GRA yöntemi kriter ağırlıklandırması yapmaz, alternatif sıralamasında kullanılır. Bu yöntemler kullanılırken öncesinde kriter ağırlıklandırma için AHP gibi bir yöntemin kullanılması gerekir.

Literatür bölümünde de verildiği üzere hem kriter ağırlıklandırması için hem de alternatiflerin sıralanması için birçok farklı yöntem bulunmaktadır. Kriter ağırlıklandırıması için AHP, bulanık AHP, ANP gibi yöntemler kullanılmaktadır. Alternatiflerin sıralanması için ise DEMATEL, PROMETHEE, MOORA, ARAS, TOPSIS, GRA gibi yöntemler önerilmektedir. ÇKKV yöntemleri farklı matematiksel altyapılar kullanmaktadır ve aynı problemlere farklı yöntemlerin uygulanmasıyla farklı sonuçlar elde edilebilir.

Bu çalışmada bir büyükşehir belediyesinde, metro sürücüsü seçimi için, literatürdeki yöntemler bütünleşik olarak kullanılarak yeni bir personel seçimi uygulaması geliştirilmiştir. Uygulamada ilk olarak AHP yöntemi kullanılarak kriterler ağırlıklandırılmış, daha sonra GRA ve TOPSIS yöntemleri kullanılarak personellerin sıralamaları yapılmıştır. Önerilen süreçte farklı iki yöntem kullanılarak elde edilen sonuçlar kıyaslanmıştır. Bu sayede çalışmanın daha tutarlı olması amaçlanmıştır. Çalışmada önetilen uygulama modeli Şekil 1'de görülebilir. 
Şekil 1: Önerilen Uygulama Modeli

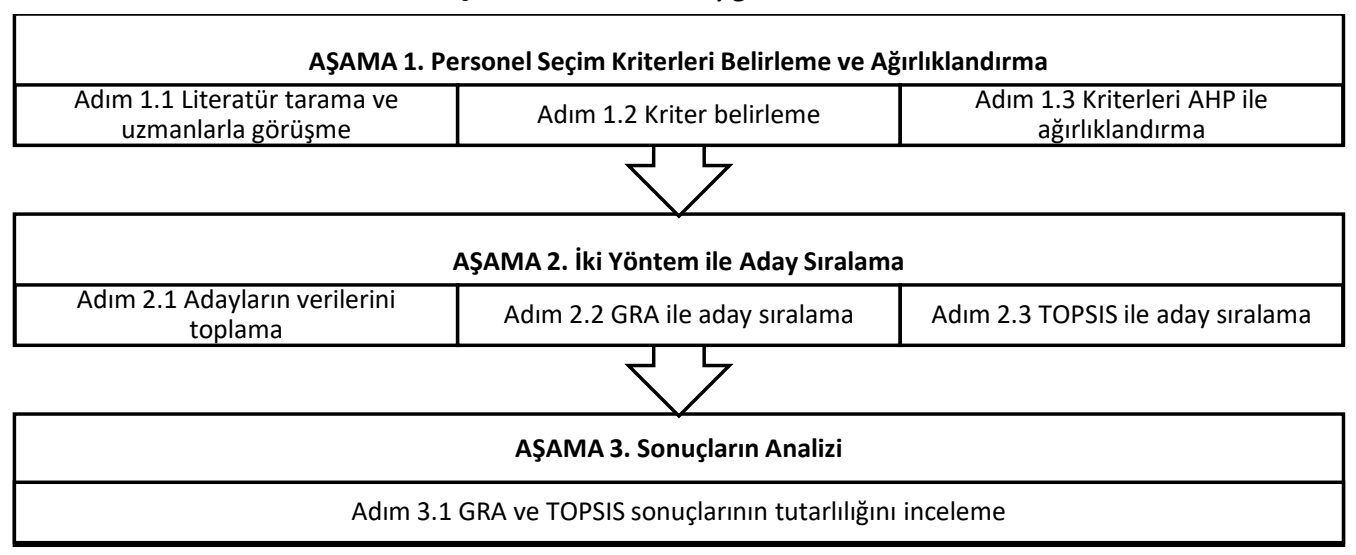

\section{Uygulama}

Uygulamada ilk olarak, literatür araştırması ve uzman görüşmeleri sonucunda personel seçimi için gerekli kriterler belirlenmiştir. 5 ana kriter ve 13 tane alt kriter kullanılmaktadır. Kriterler özgeçmişlerin kıyaslanmasında ve elenmesinde kolaylık sağlamaktadır. Belirlenen kriterler ve bu kriterlerin açıklamaları Tablo 3'te verilmiştir.

Tablo 3: Personel Seçiminde Kullanılan Kriterler

\begin{tabular}{|c|c|c|}
\hline & Alt Gösterge & Açıklama \\
\hline \multirow{3}{*}{ 1. Eğitim ve Tecrübe } & Ehliyet ve sürüş tecrübesi & $\begin{array}{l}\text { Uzmanlar tarafından adayın sürüş tecrübesi için verilen 0-10 } \\
\text { arası puan }\end{array}$ \\
\hline & Akademik & $\begin{array}{l}\text { Uzmanlar tarafından adayın akademik geçmişi için verilen 0-10 } \\
\text { arası puan }\end{array}$ \\
\hline & Yabancı dil & Adayın yabancı dil sınavından aldığı 0-100 arası puan \\
\hline \multirow{2}{*}{ 2. İletişim } & Diksiyon & $\begin{array}{l}\text { Uzmanlar tarafından adayın diksiyonuna verilen 0-10 arası } \\
\text { puan }\end{array}$ \\
\hline & Karşııklı iletişim kurma & $\begin{array}{l}\text { Uzmanlar tarafından adayın iletişim yeteneğine verilen 0-10 } \\
\text { arası puan }\end{array}$ \\
\hline \multirow{3}{*}{ 3. Fiziksel } & Kilo & $\begin{array}{l}\text { Uzmanlar tarafından adayın kilosunun pozisyona uygunluğu } \\
\text { için verilen } 0-10 \text { arası puan }\end{array}$ \\
\hline & Yaş & $\begin{array}{l}\text { Uzmanlar tarafından adayın yaşının pozisyona uygunluğu için } \\
\text { verilen } 0-10 \text { arası puan }\end{array}$ \\
\hline & Boy & $\begin{array}{l}\text { Uzmanlar tarafından adayın boyunun pozisyona uygunluğu } \\
\text { için verilen } 0-10 \text { arası puan }\end{array}$ \\
\hline \multirow{2}{*}{ 4. Devamlılık } & Sağlık durumu elverişliliği & $\begin{array}{l}\text { Adayın sağlık durumu (ameliyat, diyabet, devamlı hastalık vs.) } \\
\text { için verilen 0-10 arası puan }\end{array}$ \\
\hline & $\begin{array}{l}\text { Çalışma saatlerine uygun- } \\
\text { luk }\end{array}$ & $\begin{array}{l}\text { Adayın vardiyalı sistemde (sabah, akşam, gece vb) çalışmaya } \\
\text { uygunluğuna göre verilen } 0-10 \text { arası puan }\end{array}$ \\
\hline \multirow{3}{*}{ 5. Sinav } & Mülakat & $\begin{array}{l}\text { Uzmanlar tarafından yapılan mülakat sonucu adaya verilen } 0 \text { - } \\
10 \text { arası puan }\end{array}$ \\
\hline & Psiko-teknik test & Adayın psiko-teknik testinden aldığı 0-100 arası puan \\
\hline & Yazılı sınav & Adayın yazılı sınavdan aldığı 0-100 arası puan \\
\hline
\end{tabular}

Çalışmada, AHP yöntemine uygun olarak kriterlerin ikili olarak kıyaslandığı bir anket hazırlanmış, bu anket büyükşehir belediyesinin metro bölümünde çalışan üç insan kaynakları uzmanı tarafından doldurulmuştur. AHP yöntemi Superdecisions v3.2 programı yardımıyla uygulanarak kriter ağırlıkları elde edilmiştir. Kriter ağırlıkları Tablo 4'te görülebilir. 
Tablo 4: Kriter Ağırlıkları

\begin{tabular}{|c|c|c|c|c|c|}
\hline Ana Gösterge & Ağırlık & Siralama & Alt Gösterge & Ağırlık & Sıralama \\
\hline \multirow{3}{*}{ 1. Eğitim } & \multirow{3}{*}{0,484} & \multirow{3}{*}{1} & Ehliyet ve sürüş tecrübesi & 0,234 & 1 \\
\hline & & & Akademik & 0,215 & 2 \\
\hline & & & Yabancı dil & 0,035 & 10 \\
\hline \multirow{2}{*}{ 2. Iletişim } & \multirow{2}{*}{0,177} & \multirow{2}{*}{2} & Diksiyon & 0,119 & 3 \\
\hline & & & Karşılıklı iletişim kurma & 0,058 & 6 \\
\hline \multirow{3}{*}{ 3. Fiziksel } & \multirow{3}{*}{0,092} & \multirow{3}{*}{5} & Kilo & 0,054 & 7 \\
\hline & & & Yaş & 0,026 & 12 \\
\hline & & & Boy & 0,012 & 13 \\
\hline \multirow{2}{*}{ 4. Devamlılık } & \multirow{2}{*}{0,103} & \multirow{2}{*}{4} & Sağlık durumu elverişliliği & 0,076 & 4 \\
\hline & & & Çalışma saatlerine uygunluk & 0,027 & 11 \\
\hline \multirow{3}{*}{ 5. Sinav } & \multirow{3}{*}{0,144} & \multirow{3}{*}{3} & Mülakat & 0,036 & 9 \\
\hline & & & Psiko-teknik test & 0,066 & 5 \\
\hline & & & Yazılı sınav & 0,042 & 8 \\
\hline
\end{tabular}

Kriter ağırlıkları incelendiğinde metro sürücüsü seçiminde en önemli kriterlerin ehliyet \& sürüş tecrübesi, akademik yeterlilik ve diksiyon olduğu görülmektedir. Adayların her bir kriter için aldıkları puanın ve kriter ağırıklarının bulunduğu karar matrisi Tablo 5'te verilmiştir.

Tablo 5: Karar Matrisi

\begin{tabular}{cccccccccccccc}
\hline & \multicolumn{3}{c}{} & K 1 & \multicolumn{1}{c}{ K 2 } & \multicolumn{1}{c}{ K 3 } & \multicolumn{1}{c}{ K 4 } & \multicolumn{3}{c}{ K 5 } \\
\hline & K 1.1 & K 1.2 & K 1.3 & K 2.1 & K 2.2 & K 3.1 & K 3.2 & K 3.3 & K 4.1 & K 4.2 & K 5.1 & K 5.2 & K 5.3 \\
\hline Ağırlı & 0,234 & 0,215 & 0,035 & 0,119 & 0,058 & 0,054 & 0,026 & 0,012 & 0,076 & 0,027 & 0,036 & 0,066 & 0,042 \\
\hline Aday 1 & 9 & 10 & 75 & 9 & 10 & 10 & 9 & 8 & 8 & 9 & 9 & 85 & 90 \\
\hline Aday 2 & 10 & 9 & 80 & 10 & 9 & 9 & 9 & 7 & 8 & 9 & 8 & 90 & 80 \\
\hline Aday 3 & 9 & 8 & 60 & 10 & 8 & 8 & 7 & 6 & 8 & 10 & 7 & 70 & 80 \\
\hline Aday 4 & 8 & 6 & 50 & 7 & 8 & 9 & 8 & 7 & 9 & 8 & 7 & 60 & 70 \\
\hline
\end{tabular}

Karar matrisinin elde edilmesinden sonra TOPSIS yöntemi uygulanmıştır. TOPSIS yönteminin uygulama adımları Tablo 6'da verilmiştir.

Tablo 6: TOPSIS Yöntemi Uygulama Adımları

\begin{tabular}{|c|c|c|c|c|c|c|c|c|c|c|c|c|c|}
\hline & \multicolumn{3}{|c|}{ K 1} & \multicolumn{2}{|c|}{ K 2} & \multicolumn{3}{|c|}{ K 3} & \multicolumn{2}{|c|}{ K 4} & \multicolumn{3}{|c|}{ K 5} \\
\hline & K 1.1 & K 1.2 & K 1.3 & K 2.1 & K 2.2 & K 3.1 & K 3.2 & K 3.3 & K 4.1 & K 4.2 & K 5.1 & K 5.2 & K 5.3 \\
\hline Ağırlık & 0,234 & 0,215 & 0,035 & 0,119 & 0,058 & 0,054 & 0,026 & 0,012 & 0,076 & 0,027 & 0,036 & 0,066 & 0,042 \\
\hline Aday 1 & 10 & 9 & 80 & 10 & 9 & 9 & 9 & 7 & 8 & 9 & 8 & 90 & 80 \\
\hline Aday 2 & 9 & 10 & 75 & 9 & 10 & 9 & 9 & 8 & 8 & 8 & 8 & 80 & 90 \\
\hline Aday 3 & 9 & 8 & 60 & 10 & 8 & 8 & 7 & 6 & 8 & 10 & 7 & 70 & 80 \\
\hline Aday 4 & 8 & 6 & 50 & 7 & 8 & 9 & 8 & 7 & 9 & 8 & 7 & 60 & 70 \\
\hline \multicolumn{14}{|c|}{ Nomalize matrisin oluşturulması } \\
\hline Aday 1 & 0,554 & 0,537 & 0,594 & 0,550 & 0,512 & 0,514 & 0,543 & 0,497 & 0,484 & 0,512 & 0,532 & 0,593 & 0,498 \\
\hline Aday 2 & 0,498 & 0,597 & 0,557 & 0,495 & 0,569 & 0,514 & 0,543 & 0,569 & 0,484 & 0,455 & 0,532 & 0,528 & 0,560 \\
\hline Aday 3 & 0,498 & 0,477 & 0,446 & 0,550 & 0,455 & 0,457 & 0,422 & 0,426 & 0,484 & 0,569 & 0,466 & 0,462 & 0,498 \\
\hline Aday 4 & 0,443 & 0,358 & 0,371 & 0,385 & 0,455 & 0,514 & 0,482 & 0,497 & 0,545 & 0,455 & 0,466 & 0,396 & 0,436 \\
\hline \multicolumn{14}{|c|}{ Ağırlıklandırılmış normalize matrisin oluşturulması } \\
\hline Aday 1 & 0,130 & 0,116 & 0,021 & 0,065 & 0,030 & 0,028 & 0,014 & 0,006 & 0,037 & 0,014 & 0,019 & 0,039 & 0,021 \\
\hline Aday 2 & 0,117 & 0,128 & 0,019 & 0,059 & 0,033 & 0,028 & 0,014 & 0,007 & 0,037 & 0,012 & 0,019 & 0,035 & 0,024 \\
\hline Aday 3 & 0,117 & 0,103 & 0,016 & 0,065 & 0,026 & 0,025 & 0,011 & 0,005 & 0,037 & 0,015 & 0,017 & 0,030 & 0,021 \\
\hline Aday 4 & 0,104 & 0,077 & 0,013 & 0,046 & 0,026 & 0,028 & 0,012 & 0,006 & 0,041 & 0,012 & 0,017 & 0,026 & 0,019 \\
\hline
\end{tabular}


Eskişehir Osmangazi Üniversitesi ïBF Dergisi

\begin{tabular}{|c|c|c|c|c|c|c|c|c|c|c|c|c|c|}
\hline \multicolumn{14}{|c|}{ İdeal negatif ve pozitiflerin belirlenmesi } \\
\hline $\mathbf{V}^{*}$ & 0,130 & 0,128 & 0,021 & 0,065 & 0,033 & 0,028 & 0,014 & 0,007 & 0,041 & 0,015 & 0,019 & 0,039 & 0,024 \\
\hline $\mathbf{V}^{-}$ & 0,104 & 0,077 & 0,013 & 0,046 & 0,026 & 0,025 & 0,011 & 0,005 & 0,037 & 0,012 & 0,017 & 0,026 & 0,019 \\
\hline
\end{tabular}

İdeal negatif ve pozitiflerin belirlenmesinden sonra son her adayın ideal pozitif ve negatife olan uzaklıkları belirlenerek, bu uzaklıklar yardımıyla adayların TOPSIS performansı hesaplanır. Adayların TOPSIS performans değerleri Tablo 7'de verilmiştir.

Tablo 7: Ideal Negatif \& Pozitife Uzaklıkları ve TOPSIS Performans Skorları

\begin{tabular}{lccc}
\hline & Si+ & Si- & Pi \\
\hline Aday 1 & 0,0144 & 0,0531 & 0,7867 \\
\hline Aday 2 & 0,0162 & 0,0565 & 0,7774 \\
\hline Aday 3 & 0,0321 & 0,0354 & 0,5247 \\
\hline Aday 4 & 0,0634 & 0,0058 & 0,0840 \\
\hline
\end{tabular}

TOPSIS yöntemiyle adayların performans skorları elde edildikten sonra GRA yöntemi uygulanarak sonuçların tutarlılığı analiz edilir. GRA yönteminin uygulama adımları Tablo 8'de görülebilir.

Tablo 8: GRA Yöntemi Uygulama Adımları

\begin{tabular}{|c|c|c|c|c|c|c|c|c|c|c|c|c|c|}
\hline & \multicolumn{3}{|c|}{ K 1} & \multicolumn{2}{|c|}{ K 2} & \multicolumn{3}{|c|}{ K 3} & \multicolumn{2}{|c|}{ K 4} & \multicolumn{3}{|c|}{$K 5$} \\
\hline & K 1.1 & K 1.2 & K 1.3 & K 2.1 & K 2.2 & K 3.1 & K 3.2 & K 3.3 & K 4.1 & K 4.2 & K 5.1 & K 5.2 & K 5.3 \\
\hline Aday 1 & 10 & 9 & 80 & 10 & 9 & 9 & 9 & 7 & 8 & 9 & 8 & 90 & 80 \\
\hline Aday 2 & 9 & 10 & 75 & 9 & 10 & 9 & 9 & 8 & 8 & 8 & 8 & 80 & 90 \\
\hline Aday 3 & 9 & 8 & 60 & 10 & 8 & 8 & 7 & 6 & 8 & 10 & 7 & 70 & 80 \\
\hline Aday 4 & 8 & 6 & 50 & 7 & 8 & 9 & 8 & 7 & 9 & 8 & 7 & 60 & 70 \\
\hline Ortalama & 9 & 8,25 & 66,25 & 9 & 8,75 & 8,75 & 8,25 & 7 & 8,25 & 8,75 & 7,5 & 75 & 80 \\
\hline \multicolumn{14}{|c|}{ Normalizasyon Matrisi } \\
\hline Aday 1 & 1,000 & 0,750 & 1,000 & 1,000 & 0,500 & 1,000 & 1,000 & 0,500 & 0,000 & 0,500 & 1,000 & 1,000 & 0,500 \\
\hline Aday 2 & 0,500 & 1,000 & 0,833 & 0,667 & 1,000 & 1,000 & 1,000 & 1,000 & 0,000 & 0,000 & 1,000 & 0,667 & 1,000 \\
\hline Aday 3 & 0,500 & 0,500 & 0,333 & 1,000 & 0,000 & 0,000 & 0,000 & 0,000 & 0,000 & 1,000 & 0,000 & 0,333 & 0,500 \\
\hline Aday 4 & 0,000 & 0,000 & 0,000 & 0,000 & 0,000 & 1,000 & 0,500 & 0,500 & 1,000 & 0,000 & 0,000 & 0,000 & 0,000 \\
\hline Standart Seri & 1 & 1 & 1 & 1 & 1 & 1 & 1 & 1 & 1 & 1 & 1 & 1 & 1 \\
\hline \multicolumn{14}{|c|}{ Mutlak Değer Matrisi } \\
\hline Aday 1 & 0,000 & 0,250 & 0,000 & 0,000 & 0,500 & 0,000 & 0,000 & 0,500 & 1,000 & 0,500 & 0,000 & 0,000 & 0,500 \\
\hline Aday 2 & 0,500 & 0,000 & 0,167 & 0,333 & 0,000 & 0,000 & 0,000 & 0,000 & 1,000 & 1,000 & 0,000 & 0,333 & 0,000 \\
\hline Aday 3 & 0,500 & 0,500 & 0,667 & 0,000 & 1,000 & 1,000 & 1,000 & 1,000 & 1,000 & 0,000 & 1,000 & 0,667 & 0,500 \\
\hline Aday 4 & 1,000 & 1,000 & 1,000 & 1,000 & 1,000 & 0,000 & 0,500 & 0,500 & 0,000 & 1,000 & 1,000 & 1,000 & 1,000 \\
\hline \multicolumn{14}{|c|}{ Gri İlişki Katsayıları Matrisi } \\
\hline Aday 1 & 1,000 & 0,800 & 1,000 & 1,000 & 0,667 & 1,000 & 1,000 & 0,667 & 0,500 & 0,667 & 1,000 & 1,000 & 0,667 \\
\hline Aday 2 & 0,667 & 1,000 & 0,857 & 0,750 & 1,000 & 1,000 & 1,000 & 1,000 & 0,500 & 0,500 & 1,000 & 0,750 & 1,000 \\
\hline Aday 3 & 0,667 & 0,667 & 0,600 & 1,000 & 0,500 & 0,500 & 0,500 & 0,500 & 0,500 & 1,000 & 0,500 & 0,600 & 0,667 \\
\hline Aday 4 & 0,500 & 0,500 & 0,500 & 0,500 & 0,500 & 1,000 & 0,667 & 0,667 & 1,000 & 0,500 & 0,500 & 0,500 & 0,500 \\
\hline Ağırlıklar & 0,234 & 0,215 & 0,035 & 0,119 & 0,058 & 0,054 & 0,026 & 0,012 & 0,076 & 0,027 & 0,036 & 0,066 & 0,042 \\
\hline \multicolumn{14}{|c|}{ Ağırlıklandırılmış Gri îlişki Matrisi } \\
\hline Aday 1 & 0,234 & 0,172 & 0,035 & 0,119 & 0,039 & 0,054 & 0,026 & 0,008 & 0,038 & 0,018 & 0,036 & 0,066 & 0,028 \\
\hline Aday 2 & 0,156 & 0,215 & 0,030 & 0,089 & 0,058 & 0,054 & 0,026 & 0,012 & 0,038 & 0,013 & 0,036 & 0,049 & 0,042 \\
\hline Aday 3 & 0,156 & 0,144 & 0,021 & 0,119 & 0,029 & 0,027 & 0,013 & 0,006 & 0,038 & 0,027 & 0,018 & 0,039 & 0,028 \\
\hline Aday 4 & 0,117 & 0,108 & 0,017 & 0,059 & 0,029 & 0,054 & 0,017 & 0,008 & 0,076 & 0,013 & 0,018 & 0,033 & 0,021 \\
\hline
\end{tabular}


Son aşamada ağırlıklandırılmış gri ilişki matrisinin satır değerleri toplanarak her adayın GRA skoru elde edilir. Adayların gri ilişki skorları Tablo 9'da görülebilir.

\begin{tabular}{|c|c|}
\hline & $\Gamma$ \\
\hline Aday 1 & 0,8728 \\
\hline Aday 2 & 0,8197 \\
\hline Aday 3 & 0,6650 \\
\hline Aday 4 & 0,5714 \\
\hline
\end{tabular}

Aday sıralama, ilk olarak TOPSIS yöntemi ile daha sonra GRA yöntemi ile yapılmıştır. İki yöntemin sonuçlarına göre elde edilen performans indeksleri ve aday sıralamaları Tablo 10 'da verilmiştir.

Tablo 10: Adayların TOPSIS ve GRA Skorları

\begin{tabular}{cccc}
\hline Adaylar & GRA Sonuçları & TOPSIS Sonuçları & Sıralama \\
\hline Aday 1 & 0,8728 & 0,7867 & 1 \\
\hline Aday 2 & 0,8197 & 0,7774 & 2 \\
\hline Aday 3 & 0,6650 & 0,5247 & 3 \\
\hline Aday 4 & 0,5714 & 0,0840 & 4 \\
\hline
\end{tabular}

Hem GRA yöntemi sonuçlarına göre hem de TOPSIS sonuçlarına göre Aday 1 ilk sıradadır ve ardından Aday 2, 3 ve 4 gelmektedir. Adayların skorları farklı olmasına rağmen sıralamaları aynıdır. Bu durumda uygulama sonuçlarının tutarlı olduğu ve güvenilir bir sonuç verdiği söylenebilir. İse alımda ilk olarak Aday 1 'in tercih edilmesi isabetli olaraktır.

GRA yönteminin değerlendirme ölçeği “ $0,5-1,0$ ” aralığında iken, TOPSIS yönteminin değerlendirme ölçeği " $0,0-1,0$ ” aralığındadır. Bu nedenle skorların farklı çıkması normaldir. Ayrıca TOPSIS yönteminin skor aralığı daha geniş olduğu için, sonuç hassasiyetinin daha fazla olduğu söylenebilir.

\section{Sonuç}

Bu çalışmada, bir büyükşehir belediyesinde çalışacak metro sürücüsü seçilmesi için ÇKKV yöntemleri kullanılarak yeni bir personel seçme süreci önerilmiştir. ilk olarak kriterler belirlenmiş ve AHP yöntemi ile bu kriterler ağılıklandırılmıştır. Metro sürücüsü seçiminde en önemli kriterlerin ehliyet \& sürüş tecrübesi, akademik yeterlilik ve diksiyon olduğu sonucuna ulaşılmıştır. Daha sonra, GRA ve TOPSIS yöntemleri ile adaylar sıralandığında, her iki yöntem sonucunda da sıralamalar aynı çıkmıştır. Bu da çalışmanın tutarlı ve güvenilir olduğunu göstermektedir.

AHP yöntemi ikili kıyaslamaya dayalı ve fazla veri girişi isteyen bir yöntemdir ancak kriter ağırlıklandırması için literatürde kullanılan en güçlü yöntemlerden biridir. Ayrıca "Superdecisions" paket programı ile kullanımı basittir. GRA ve TOPSIS yöntemleri ise güçlü matematiksel temele sahiptir ve özel bir paket program olmadan kullanılabilirler.

Çalışmada çok kriterli karar verme yöntemleri hem entegre olarak kullanılmış hem de alternatiflerin sıralanması aşamasında iki farklı yöntem kullanılarak sonucun güvenilirliği ve tutarlılığı incelenmiştir. Bu çalışma, literatürde metro sürücüsü seçimi için yapılan bilinen ilk çalışmadır. Ayrıca iki farklı yöntem kullanarak sonuçların tutarlıı̆̆ını inceleyen nadir çalışmalardan biridir. 
Eskişehir Osmangazi Üniversitesi ïBF Dergisi

Gelecekte, metro sürücüsü seçimi için farklı kriterler kullanılarak benzer bir çalışma yapılabilir. Ayrıca, aynı kriterler kullanılarak farklı ÇKKV yöntemleri de kullanılabilir. Böylece farklı yöntemler ile elde edilen sonuçlar birbirleriyle kıyaslanabilir. 


\section{Kaynaklar}

Ablhamid, Ramadan Krebish; Santoso, Budi; Muslim, M Aziz (2013), “Decision Making and Evaluation System for Employee Recruitment Using Fuzzy Analytic Hierarchy Process", International Refereed Journal of Engineering and Science, C. 2, S. 7: 24-31.

Adıgüzel, Orhan (2009), "Personel Seçiminin Analitik Hiyerarşi Prosesi Yöntemiyle Gerçekleştirilmesi”, Dumlupınar Üniversitesi Sosyal Bilimler Dergisi, C. 24: 243-251.

Afshari, Alireza; Mojahed, Majid; Yusuff Mohd, Rosnah; Hong Tang Sai; Ismail Yusof (2010), "Personel Selection Using ELECTRE", Journal of Applied Sciences, C. 10, S. 23: 3068-3075.

Afshari, Alireza; Mojahed, Majid; Yusuff Mohd, Rosnah (2010), "Simple additive weighting approach to personnel selection problem", International Journal of Innovation, Management and Technology, C. 1, S. 5: 511-515.

Ak, Muhammet Fatih; Gul, Muhammet (2019), "AHP-TOPSIS integration extended with Pythagorean fuzzy sets for information security risk analysis", Complex \& Intelligent Systems, C. 5, S. 2: 113-126.

Akça, Nesrin; Sönmez, Seda; Gür, Şeyda; Yılmaz, Ali; Eren, Tamer (2018), "Kamu Hastanelerinde Analitik Ağ Süreci Yöntemi ile Finans Yöneticisi Seçimi”, Optimum Ekonomi ve Yönetim Bilimleri Dergisi, C. 5, S. 2: 133-146.

Akın, Nalan Gülten (2016), "Personel Seçiminde Çok Kriterli Karar Verme: Bulanık Topsis Uygulaması - Multi-Criteria Approach to Personnel Selection: Fuzzy Topsis Applications", Journal of Business Research - Turk, C. 8, S. 2: 224254.

Aksakal, Erdem; Dağdeviren, Metin (2010), “ANP ve DEMATEL Yöntemleri İle Personel Seçimi Problemine Bütünleşik Bir Yaklaşım", Journal of the Faculty of Engineering and Architecture of Gazi University, C. 25, S. 4: 905-913.

Bedir, Neşet; Eren, Tamer (2015), “AHP-PROMETHEE Yöntemleri Entegrasyonu ile Personel Seçim Problemi : Perakende Sektöründe Bir Uygulama”, Social Sciences Research Journal, C. 4, S. 4: 46-58.

Dağdeviren, Metin (2007), "Bulanık Analitik Hiyerarşi Prosesi ile Personel Seçimi Ve Bir Uygulama”, Journal of the Faculty of Engineering and Architecture of Gazi University, C. 22, S.4: 791-799.

Dağdeviren, Metin; Dönmez, Nilay; Kurt, Mustafa (2006), “Bir İşletmede Tedarikçi Değerlendirme Süreci İçin Yeni Bir Model Tasarımı Ve Uygulaması”, Gazi Üniversitesi Mühendislik-Mimarlık Fakültesi Dergisi, C. 21, S. 2: 247-255.

Dağdeviren, Metin; Eren, Tamer (2001) "Tedarikçi Firma Seçiminde Analitik Hiyerarşi Prosesi Ve 0-1 Hedef Programlama Yöntemlerinin Kullanılması", Journal of the Faculty of Engineering and Architecture of Gazi University, C. 16, S. 2: 41-52.

Değermenci, Aleyna; Ayvaz, Berk (2016), "Bulanık Ortamda Topsis Yontemi ile Personel Secimi : Katılım Bankacılıgı Sektorunde Bir Uygulama”, İstanbul Ticaret Üniversitesi Fen Bilimleri Dergisi, C. 15, S. 30: 77-93.

Doğan, Altan; Önder, Emrah (2014), “İnsan Kaynakları Temin Ve Seçiminde Çok Kriterli Karar Verme Tekniklerinin Kullanılması Ve Bir Uygulama", Journal of Yaşar University, C. 9, S. 34: 5796-5819.

Efe, Burak; Kurt, Mustafa (2018) “Bir Liman İşletmesinde Personel Seçimi Uygulaması”. Karaelmas Fen ve Mühendislik Dergisi, C. 8, S. 2: 417-427.

Eren, Emre; Tuzkaya, Umut Rifat (2019), “Occupational health and safety-oriented medical waste management: A case study of Istanbul”, Waste Management and Research, C. 37, S. 9: 876-884.

Eroğlu, Ergün; Yıldırım, Bahadır; Özdemir, Muhlis (2014), “Çok Kriterli Karar Vermede 'Oreste' Yöntemi Ve Personel Seçiminde Uygulanması", Istanbul Management Journal, C. 25, S. 76: 1-19.

Ilgaz Yıldırım, B.; Uysal, F; Ilgaz, A. (2019), "Havayolu İ̧̧letmelerinde Personel Seçimi: Aras Yöntemi İle Bir Uygulama", Süleyman Demirel Üniversitesi Sosyal Bilimler Enstitüsü Dergisi, C. 2, S. 33: 219-231.

Karagöz, Serhat (2009), “Tedarik Zinciri Yönetiminde Tedarikçi Seçimi Ve Ahp ille Uygulanması”, Pamukkale Üniversitesi Sosyal Bilimler Enstitüsü Yüksek Lisans Tezi.

Korkusuz, Ammar Yasir; Inan, Umut Hulusi; Ozdemir, Yavuz; Basligil, Huseyin (2018), "Evaluation of Occupational Health and Safety Key Performance Indicators Using in Healthcare Sector", Sigma Journal of Engineering and Natural Sciences-Sigma Muhendislik Ve Fen Bilimleri Dergisi, C. 36, S. 3: 705-715.

Korkusuz, Ammar Yasir; Inan, Umut Hulusi; Ozdemir, Yavuz; Basligil, Huseyin (2020), "Occupational health and safety performance measurement in healthcare sector using integrated multi criteria decision making methods", Journal of the Faculty of Engineering and Architecture of Gazi University, C. 35, S. 1: 81-96.

Kuşakçı, Ali Osman; Ayvaz, Berk; Öztürk, Fatih; Sofu, Feyza (2019), "Bulanik Multimoora lile Personel Seçimi: Havacılık Sektöründe Bir Uygulama”, Ömer Halisdemir Üniversitesi Mühendislik Bilimleri Dergisi, C. 8, S. 1: 96-110. 


\section{Eskişehir Osmangazi Üniversitesi IïBF Dergisi}

Özbek, Aşır (2014), "Yöneticilerin Çok Kriterli Karar Verme Yöntemi ille Belirlenmesi", Journal of Management and Economics Research, C. 24: 209-225.

Özdağoğlu, Aşkın; Güler, Mehmet Emre, (2016) "E-Service Quality of Internet Based Banking Using Combined Fuzzy AHP and Fuzzy TOPSIS", Tehnički vjesnik, C. 23, S. 2: 589-598.

Özdemir, Yavuz; Başlıgil, Hüseyin; Ak, Muhammet Fatih (2016), “Airport Safety Risk Evaluation Based On Fuzzy ANP And Fuzzy AHP", Uncertainty Modelling in Knowledge Engineering and Decision Making Proceedings of the 12th International FLINS Conference Proceedings, 1056-1062.

Özdemir, Yavuz; Nalbant, Kemal Gökhan (2018), "A Real Personnel Selection Problem Using The Generalized Choquet Integral Methodology", Business \& Management Studies: An International Journal, C. 6, S. 2: 694-716.

Özdemir, Yavuz; Nalbant, Kemal Gökhan; Başlıgil, Hüseyin (2017), "Evaluation of Personnel Selection Criteria Using Consistent Fuzzy Preference Relations", International Journal of Management Science, C. 4, S. 6: 76-81.

Saaty, Rozann Whitaker (1987), "The analytic hierarchy process-what it is and how it is used", Mathematical Modelling, C. 9, S. 3-5: 161-176.

Saaty, Thomas L. (1990), "How to make a decision: The Analytic Hierarchy Process", European Journal of Operational Research, C. 48: 9-26.

Tepe, Serap; Görener, Ali (2014), “Analitik hiyerarşi süreci ve moora yöntemlerinin personel seçiminde uygulanması", Istanbul Ticaret Üniversitesi Fen Bilimleri Dergisi, C. 13, S. 25: 1-14.

Tepe, Serap; Kaya, insan (2019), "A fuzzy-based risk assessment model for evaluations of hazards with a real-case study", Human and Ecological Risk Assessment: An International Journal, C. 26, S. 2: 1-26.

Tureli, Nesrin ŞalvarcI; Davraz, Gonca Manap (2016), "Use of AHP and VIKOR Method in Personnel Selection in the Service Sector: An Investigation in terms of private hospitals", The Journal of Academic Social Science Studies, C. 44: 249-262.

Tzeng, Gwo-Hshiung; Huang, Jih-Jeng (2011), Multiple Attribute Decision Making Methods And Applications, Boca Raton: CRC Press Taylor \& Francis Group.

Uzun, Sümeyra; Kazan, Halim (2016), “Çok Kriterli Karar Verme Yöntemlerinden AHP TOPSIS ve PROMETHEE Karşıllaştırılması: Gemi İnşada Ana Makine Seçimi Uygulaması", Journal of Transportation and Logistics, C. 1, S. 1: 99-113.

Vatansever, Kemal; Akgül, Yakup (2018) "Performance evaluation of websites using entropy and grey relational analysis methods: The case of airline companies", Decision Science Letters, C. 7: 119-130.

Yıldız, Ayşe; Deveci, Muhammed (2013), "Bulanık VIKOR Yöntemine Dayalı Personel Seçim Süreci”, Ege Academic Review, C. 13, S. 4: 427-436.

Yıldız, Mehmet Selami; Aksoy, Selman (2015), “Analitik Hiyerarşi Prosesi Ille Personel Seçimi Üzerine Bir Çalışma”, AIBU Journal of Social Sciences, C. 15, S. 1: 59-83. 


\section{Extended Summary}

\section{Metro Driver Selection by Using Multi Criteria Decision Making Methods}

In this study, MCDM (Multi Criteria Decision Making) methods were used to solve the personnel selection problem, which is one of the most important issues for profit of companies. Firstly, the criteria for metro driver selection were determined and these criteria were weighted by AHP method. Later, the candidates were ranked using TOPSIS and GRA methods by collecting the candidates' criteria data. The results of the two different methods were similar. Candidates are ranked by two different methods, and similar results show the consistency of the study. According to the authors' knowledge, this study is one of the rare studies that analyze the consistency of the results by using two different methods and the first study that used the MCDM methods in the selection of metro drivers in the literature.

The purpose of this study is to develop an objective and consistent application in order to solve the problem of metro driver selection. To achieve this, integrated multi-criteria decision-making methods were used. Moreover, two different methods were used to analyze the consistency of the results.

Many different methods have been proposed in literature both for criteria weighting and for alternative ranking. Methods such as AHP, fuzzy AHP, ANP are used for criterion weighting. Methods such as DEMATEL, PROMETHEE, MOORA, ARAS, TOPSIS, GRA are recommended for alternative ranking. MCDM methods use different mathematical models, that's why different results can be obtained by applying different methods to the same problem.

AHP method is one of the most widely used criteria weighting methods in the literature. Different criteria do not have the same weight on the results. AHP method was used in this study to determine the weights of different criteria on alternative selection.

TOPSIS and GRA methods can take numerical criteria data in different scales as input. In the personnel selection problem, the numerical criteria scales may not be the same (score given by experts, exam result, etc.). In this case, TOPSIS and GRA methods can be used. Both TOPSIS method and GRA method do not make criteria weighting, they are used in alternative ranking. While using these methods, AHP method was used for criteria weighting.

New personnel selection application was developed for the metro driver selection in a metropolitan municipality by using MCDM methods in an integrated manner. Criteria were weighted first by using the AHP method, and then the staff were ranked using the GRA and TOPSIS methods. In the proposed application, the results obtained by two different methods were compared. In this way, it is aimed to observe the consistency of the results. Application model can be seen in Figure 2.

Figure 2: Proposed Model

\begin{tabular}{|l|c|c|}
\hline \multicolumn{4}{|c|}{ STAGE 1. Determination and Weighting of Personnel Selection Criteria } \\
\hline $\begin{array}{c}\text { Step 1.1 Literature review and } \\
\text { interview with experts }\end{array}$ & Step 1.2 Setting criteria & $\begin{array}{c}\text { Step 1.3 Weighting Criteria with } \\
\text { AHP }\end{array}$ \\
\hline \multicolumn{3}{|c|}{ STAGE 2. Ranking by Two Methods } \\
\hline Step 2.1 Collecting candidates' data & Step 2.2 Ranking candidates with & $\begin{array}{c}\text { Step 2.3 Ranking candidates with } \\
\text { TOPSIS }\end{array}$ \\
\hline
\end{tabular}

After literature research and expert interviews, the criteria have been determined for the selection of metro driver. 5 main criteria and 13 sub criteria were determined. Then these criteria were weighted by using AHP method. The determined criteria and their weights are given in Table 11.

Table 11: Criterion List and Their Weights

\begin{tabular}{|c|c|c|c|c|c|}
\hline Main Criterion & Weight & Ranking & Sub Criterion & Weight & Ranking \\
\hline \multirow{2}{*}{ 1. Education } & \multirow{2}{*}{0,484} & \multirow{2}{*}{1} & Driving license \& experience & 0,234 & 1 \\
\hline & & & Academic & 0,215 & 2 \\
\hline
\end{tabular}


Eskişehir Osmangazi Üniversitesi iißBF Dergisi

\begin{tabular}{|c|c|c|c|c|c|}
\hline & & & \\
\hline & & & Foreign language & 0,035 & 10 \\
\hline \multirow{2}{*}{ 2. Communication } & \multirow{2}{*}{0,177} & \multirow{2}{*}{2} & Diction & 0,119 & 3 \\
\hline & & & Mutual communication & 0,058 & 6 \\
\hline \multirow{3}{*}{ 3. Physical } & \multirow{3}{*}{0,092} & \multirow{3}{*}{5} & Weight & 0,054 & 7 \\
\hline & & & Age & 0,026 & 12 \\
\hline & & & Height & 0,012 & 13 \\
\hline \multirow{2}{*}{ 4. Availability } & \multirow{2}{*}{0,103} & \multirow{2}{*}{4} & Health status availability & 0,076 & 4 \\
\hline & & & Suitability for working hours & 0,027 & 11 \\
\hline \multirow{3}{*}{ 5. Exam } & \multirow{3}{*}{0,144} & \multirow{3}{*}{3} & Interviews & 0,036 & 9 \\
\hline & & & Psycho-technical test & 0,066 & 5 \\
\hline & & & Written exam & 0,042 & 8 \\
\hline
\end{tabular}

The most important criteria in choosing the subway driver are driving license \& experience, academic competence and diction. The decision matrix, with criterion weights and collected data from the candidates, is given in Table 12.

Table 12: Decision Matrix

\begin{tabular}{ccccccccccccccc}
\hline & \multicolumn{3}{c}{} & K 1 & \multicolumn{4}{c}{ K 2 } & \multicolumn{3}{c}{ K 3 } & \multicolumn{1}{c}{ K 4 } & \multicolumn{1}{c}{ K 5 } \\
\hline & K 1.1 & K 1.2 & K 1.3 & K 2.1 & K 2.2 & K 3.1 & K 3.2 & K 3.3 & K 4.1 & K 4.2 & K 5.1 & K 5.2 & K 5.3 \\
\hline Weight & 0,234 & 0,215 & 0,035 & 0,119 & 0,058 & 0,054 & 0,026 & 0,012 & 0,076 & 0,027 & 0,036 & 0,066 & 0,042 \\
\hline Candidate 1 & 9 & 10 & 75 & 9 & 10 & 10 & 9 & 8 & 8 & 9 & 9 & 85 & 90 \\
\hline Candidate 2 & 10 & 9 & 80 & 10 & 9 & 9 & 9 & 7 & 8 & 9 & 8 & 90 & 80 \\
\hline Candidate 3 & 9 & 8 & 60 & 10 & 8 & 8 & 7 & 6 & 8 & 10 & 7 & 70 & 80 \\
\hline Candidate 4 & 8 & 6 & 50 & 7 & 8 & 9 & 8 & 7 & 9 & 8 & 7 & 60 & 70 \\
\hline
\end{tabular}

Candidate ranking was conducted first with the TOPSIS method and then with the GRA method. Performance scores and candidate rankings, obtained by two methods, are given in Table 13.

Table 13: TOPSIS and GRA Scores

\begin{tabular}{lccc}
\hline Candidates & GRA Results & TOPSIS Results & Ranking \\
\hline Candidate 1 & 0,8728 & 0,7867 & 1 \\
\hline Candidate 2 & 0,8197 & 0,7774 & 2 \\
\hline Candidate 3 & 0,6650 & 0,5247 & 3 \\
\hline Candidate 4 & 0,5714 & 0,0840 & 4 \\
\hline
\end{tabular}

According to both results of GRA and TOPSIS methods, Candidate 1 ranks first, followed by Candidate 2, 3 and 4. Although the scores of the candidates are different, their rankings are the same. In this case, it can be said that the application results are consistent and it gives a reliable result. It is appropriate to choose Candidate 1 in recruitment. While the evaluation scale of the GRA method is in the range of " $0.5-1.0$ ", the evaluation scale of the TOPSIS method is in the range of "0.0 - 1.0". Therefore, it can be said that the sensitivity of the TOPSIS method is higher.

In this study, multi-criteria decision-making methods were used in an integrated way. AHP, TOPSIS and GRA methods were chosen to solve metro driver selection problem. AHP is one of the most powerful methods used in the literature for criterion weighting. GRA and TOPSIS methods have a strong mathematical foundation.

Reliability and consistency of the result were examined by using two different methods in the ranking of alternatives. This study is the first known work in the literature, in order to select metro driver. It is also one of the rare studies that examines the consistency of results by using two different methods.

In the future, a similar study can be done by using different criteria for choosing a metro driver. In addition, different MCDM methods can be used with the same criteria and the results obtained by different methods can be compared with each other. 